\section{Edycaçäa



ARTIGO

\section{Editor}

Maria Inês Côrte Vitoria PUCRS, RS, Brasil

\section{Equipe Editorial}

Pricila Kohls dos Santos PUCRS, RS, Brasil

Marcelo Oliveira da Silva PUCRS, RS, Brasil

Carla Spagnolo

PUCRS, RS, Brasil

Rosa Maria Rigo

PUCRS, RS, Brasil

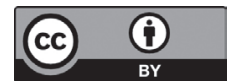

A matéria publicada neste periódico é licenciada sob forma de uma Licença Creative Commons - Atribuição 4.0 Internacional. http://creativecommons.org/licenses/by/4.0/

\title{
Gestão Social da (in)disciplina na escola e a educação para a cidadania
}

\author{
Social management of the school (in)discipline and education for citizenship
}

\author{
Luciano Henrique Barcelos ${ }^{a}$ \\ Maria Lúcia Miranda Afonso ${ }^{b}$
}

RESUMO: Este artigo discute as relações entre a gestão social da (in)disciplina na escola e a formação para a cidadania. Inicialmente, faz uma revisão de literatura sobre a (in)disciplina na escola e suas possíveis gêneses, do ponto de vista sociocultural, das interações entre família e escola, dos conflitos interpessoais e subjetivos. Defende que a educação para a cidadania e os direitos humanos constitui uma referência contemporânea fundamental para tal compreensão. Comenta o Plano Nacional de Educação em Direitos Humanos e suas proposições para o ensino fundamental, considerando o seu impacto para a discussão da (in)disciplina na escola. Argumenta que a educação para a cidadania não pode se limitar ao âmbito pedagógico e à transmissão de informações e precisa ser efetivada como prática social. Assim, defende que a abordagem da (in)disciplina na escola seja realizada no bojo de uma gestão escolar que se constitua como gestão social, com ênfase na cidadania e na participação dos diversos atores sociais envolvidos no campo da educação.

Palavras-chave: Educação para a cidadania. Gestão social. (In)Disciplina escolar.

ABSTRACT: The paper discusses the relationship between the social management of school (in)discipline and education for citizenship. Initially, it presents a literature review on school (in)discipline considering its possible genesis: the sociocultural viewpoint, the interaction between family and school, interpersonal conflicts and subjective elements. It argues that education for citizenship and human rights is a fundamental contemporary reference to approach school (in)discipline. It summarizes the National Plan for Human Rights Education's proposals and considers its consequences for the approach of school (in)discipline. The paper says that citizenship education cannot be limited to pedagogical framework and transmission of information but it needs to be promoted as a social practice. Thus, the paper defends that school (in)discipline shall be approached by the model of social management, with an emphasis on citizenship and participation of the varied social actors involved in the field of education.

Keywords: Education for citizenship. Social management. School (in)discipline.

a Pedagogo; Pós-Graduado em Psicopedagogia; MBA-Gestão de Instituições de Ensino; Mestre em Gestão Social, Educação e Desenvolvimento Local (Centro Universitário UNA/MG); Diretor do Colégio Maximus BH-MG; Diretor do Sindicato das Escolas Particulares de Minas Gerais; Diretor Suplente da Federação Regional dos Estabelecimentos de Ensino de Minas Gerais.<lucianohenriquebarcelos@hotmail.com>.

b Psicóloga social e clínica; Mestre e Doutora em Educação, Professora do Mestrado em Gestão Social, Educação e Desenvolvimento Local (Centro Universitário UNA/MG). <luafonso@yahoo.com>. 
_ ste artigo discute as contribuições da educação para a cidadania e da gestão social para a gestão da (in)disciplina Escolar. Inicia por uma revisão de literatura sobre a (in)disciplina na escola, com o propósito de identificar diferentes visões sobre esse fenômeno e sua gênese, buscando compreendê-lo em uma abordagem complexa. Nesta perspectiva, a (in) disciplina não é vista como um problema puramente individual ou moral, restrito ao âmbito da escola, mas precisa ser contextualizada como um problema da sociedade brasileira contemporânea, onde a cidadania e a educação em direitos humanos passaram a ser referências fundamentais.

De fato, historicamente, a questão da disciplina, como valor organizador, e da indisciplina como elemento desestruturador, tem sido invocada como fundamental ao desenvolvimento das relações pedagógicas e da formação humana (AQUINO, 1996; AQUINO, 1998; LOUREIRO; QUEIROZ, 2005; SOUZA; QUEIROZ; MENANDRO, 2010; BOARINI, 2013). O debate tomou diversas formas no campo da pedagogia. Porém a dimensão política da questão tem se tornado cada vez mais contundente à medida que a educação passou a ser definida como direito fundamental, na Constituição Federal de 1988. A expansão do ensino trouxe grandes desafios não apenas para universalização do acesso, mas, também, para a qualidade do ensino e o papel da educação na sociedade democrática. Nesse contexto, a questão da (in)disciplina na escola merece ser examinada sob um novo olhar.

No Brasil, a educação pública ampliou-se na década de 2000. O acesso das crianças e adolescentes de 07 a 14 anos ao ensino fundamental foi praticamente universalizado, passando de 94,7\% em 1998 para 97,9\% em 2008 (IBGE, PNAD 2009, p. 39). Grandes diferenças, no entanto, ainda existem no que diz respeito à qualidade do acesso e do ensino. As mudanças substanciais no acesso das crianças e adolescentes à escola não poderiam deixar de trazer novas questões para o processo educativo e para a instituição escolar. Que tensões e conflitos podem existir, hoje, na escola, no bojo desse processo histórico de expansão do acesso ainda sem garantias de uma real igualdade?

Não se poderia esperar que a acolhida a esse imenso contingente de alunos, com diferenças culturais, de valores e comportamentos, deixasse de ter impacto na escola, em todas as suas dimensões: no ensino, na produtividade, na relação professor-aluno, na relação família-escola e, sem dúvida, nos fenômenos da disciplina e da indisciplina, que se colocam como um desafio complexo e amplo. Diante dessa complexidade, busca-se compreender as diferentes visões sobre a (in)disciplina na escola, seus conflitos e tensões, bem como a possibilidade de seu enfrentamento a partir de uma visão de gestão social.

Assim, o artigo prossegue com uma revisão sobre o modelo de gestão social, da gestão escolar e das proposições do Plano Nacional de Educação em Direitos Humanos, visando compreender as suas possíveis contribuições para a abordagem da (in)disciplina na escola. 


\section{(In)Disciplina na escola: visões conflitantes sobre sua gênese e gestão}

A análise da indisciplina precisa ser necessariamente acompanhada de uma visão da disciplina na escola. Entendemos a disciplina como um modo de ser e fazer, um conjunto de valores, regras, modos de agir e de interagir articulado à organização funcional da instituição, com seus códigos, papéis sociais e suas relações com a sociedade mais ampla e o Estado. Assim, a ordem disciplinar na escola está articulada à existência social dessa instituição. Quando um dos atores sociais inseridos no contexto escolar fere esse modo de ser e de fazer, entende-se que cometeu uma indisciplina. E o que motivaria essa indisciplina? Seria um mero desvio da ordem? Uma resistência ou uma afronta a uma ordem estabelecida? A literatura aborda a indisciplina escolar por diversos ângulos e com diversos significados.

\section{A indisciplina como resistência às relações de hegemonia na sociedade}

A abordagem crítica da escola capitalista, que encontra grande expressão em Pierre Bourdieu (2003), desnuda a sua função de reprodução das relações de dominação social. A disciplina seria, então, compreendida como a criação de um habitus, ou seja, os sujeitos sociais são disciplinados de acordo com a ordem social hegemônica, internalizando valores, sentidos e relações, sem que seja necessário lembrar-lhes, em todos os momentos, os códigos sociais que conduzem e organizam seu cotidiano na instituição. Nesse sentido, a indisciplina aparece como elemento disruptivo do habitus (NOGUEIRA; NOGUEIRA, 2002).

Como analisam Cunha et al. (2009), na medida em que a ideologia dominante nega que a sociedade brasileira é estruturalmente violenta, quando a violência emerge em ato, ela é atribuída apenas aos desvios dos indivíduos ou a fenômenos esporádicos e superficiais. Um estudo de Ratto (2007) sobre livros de ocorrência de fenômenos de indisciplina na escola mostra que muitas ações são consideradas indisciplinas porque confrontam situações de imposição de normas arbitrárias ou mesmo preconceituosas. Nessa perspectiva, Peloso e Paula (2011) criticam a desvalorização (feita pela escola) das capacidades intelectuais e sociais das crianças das classes trabalhadoras e das camadas sociais pobres, que são estigmatizadas como "carentes" ou "faltosas" no que diz respeito aos recursos simbólicos e competências valorizadas pela escola. Aquino (2011) adverte que é preciso desnaturalizar a violência estrutural presente na escola.

Vares (2012) compara os paradigmas da reprodução das relações de dominação e o paradigma da resistência na escola, concluindo que há muitos elementos comuns entre estas teorias. Para ele, a visão funcionalista e conservadora, predominante até meados dos anos 1960, era incapaz de reconhecer a existência do conflito na escola e entre esta e a sociedade. No final dos anos 1960, novos movimentos sociais ligados às relações de gênero e etnia sacodem 
a sociedade. As teorias sobre a escola e a educação centram-se na discussão crítica sobre o papel da escola na reprodução social e cultural do sistema capitalista. Nos anos 1970, busca-se compreender como a escola colaborava para a manutenção do status quo. Essas teorias foram fundamentais para romper com as visões funcionalistas e acríticas. Porém, também vieram a ser questionadas pela falta de visão dinâmica e histórica das relações sociais. Autores como Freire, Giroux, McLaren e Saviani discutem as potencialidades emancipatórias do campo da educação, lançando um olhar sobre a escola como instituição que pode também contribuir para um sistema mais igualitário (VARES, 2012).

Para Vares (2012), isto não implica em negar o papel reprodutor da escola e a desigualdade social. Pelo contrário, é preciso reconhecê-lo para buscar uma transformação, visando reduzir desigualdades e ampliar o potencial emancipatório. A escola seria, assim, melhor compreendida como um campo de contradições que refletem as contradições da sociedade. Ao mostrar a necessidade de uma renovação teórica no âmbito da educação, Henry Giroux (1986 apud VARES, 2012) elabora a chamada teoria da resistência, pela qual afirma que a escola não se limita a ser reprodutora de desigualdades, mas comporta potencialidade de resistir e transformar. Essa é também a proposta de Freire $(1967 ; 2003)$, quando critica a educação como mera reprodutora de conhecimentos, por uma educação crítica e transformadora, que instiga à problematização das questões reais do contexto de vida dos educandos, ligando essa problematização à sua participação social, cultural e política.

Vares (2012) entende que ambas as visões tiveram importância fundamental: a teoria da reprodução contribuiu para romper as concepções tradicionais sobre a escola, e a teoria da resistência foi importante para resgatar a articulação entre teoria e lutas sociais. Para a educação transformadora, tudo deve passar pelo crivo da reflexão crítica: o currículo, a metodologia de ensino, a relação professor-aluno, a relação família-escola, e assim por diante.

Pensadores como Snyders (1977) e Freire (2003) incitam a conhecer a realidade social e cultural dessas crianças não para "suprir" suas carências (embora elas possam se beneficiar do conhecimento produzido pela sociedade em todas as suas dimensões), mas para construir com elas uma abordagem educativa que as valorize e efetive uma educação de qualidade.

A educação passa a ser um campo e um objeto de disputa pelo conhecimento, que está na base da igualdade na sociedade. Surgem demandas pela universalização do ensino fundamental e médio, pela igualdade de acesso à educação independentemente de sexo, etnia, e outras identidades ou condições sociais. A escola passa a ser vista em sua potencialidade de ser espaço para o exercício da cidadania, para as trocas culturais, a interação com a comunidade, enfim, abrem-se novos sentidos para a função social da escola. Ou seja, torna-se preciso conquistar a educação e a escola como territórios fundamentais para a cidadania e repensar estratégias e instrumentos de apropriação da escola pelos diversos setores sociais. 
Essa nova abordagem questiona os pilares tradicionais da educação: a relação professor-aluno, a relação famíliaescola, currículos e conteúdos escolares, dentre outros aspectos. Tudo isto se torna objeto de questionamento e transformação. Como não poderia deixar de ser, a questão da disciplina e da indisciplina também precisa ser retomada: O que é e como lidar com ela? A disciplina precisa ser um modo de ser e fazer coerente com os esforços de produção da igualdade e da cidadania. As interações dos diversos atores sociais no contexto escolar também ganham um novo sentido.

\section{A indisciplina resultante dos conflitos nas relações interpessoais no âmbito da escola}

A expansão do acesso à educação colocou, no contexto escolar, atores sociais que jamais haviam compartilhado antes o mesmo espaço social com base em uma condição de igualdade - estudantes de diferentes classes sociais, famílias com variadas tradições culturais. Também o corpo docente sofre transformações uma vez que as políticas públicas de educação demarcam novas exigências para contratação, exigem novas habilidades pedagógicas.

Nesse cenário, a indisciplina também pode resultar dos conflitos gerados nas relações interpessoais no âmbito da instituição escolar. Conflitos entre professores e alunos pela disputa de poder, em uma relação pedagógica onde o poder do professor passou a ser relativizado. A autoridade docente perde a sua base tradicional e precisa construir novas bases que ainda são tênues e imprecisas. Aquino (1998) enfatiza a necessidade de se trabalhar com o interesse do aluno, com metodologias diversas. Um ambiente de sala de aula com indisciplina pode ser um sinal de que alguma coisa não está no caminho relacionado ao campo ensino-aprendizagem. Para Aquino (1998), esse trabalho pedagógico precisa ser enfatizado em elementos fundamentais: (a) a transmissão do conhecimento, (b) a relação professor-aluno; (c) o ambiente da sala de aula, (d) o tipo de contrato pedagógico.

A importância dos educadores, nesse contexto, deve ser ressaltada. Como diz Gadotti (2008, p. 04):

Espera-se do professor do século XXI que tenha paixão de ensinar, que esteja aberto para sempre aprender, aberto ao novo, que tenha domínio técnico-pedagógico, que saiba contar estórias, isto é, que construa narrativas sedutoras para seus alunos. Espera-se que saiba pesquisar, que saiba gerenciar uma sala de aula, significar a aprendizagem dele e de seus alunos. Espera-se que saiba trabalhar em equipe, que seja solidário.

É importante ressalvar que os profissionais da educação precisam contar com condições dignas de trabalho, pois embora a precarização dessas condições não constitua uma justificativa para o empobrecimento da relação pedagógica, tampouco se deve negar que pode ter um efeito nocivo sobre o trabalho educativo. Nesse sentido, Vasconcellos (2006) 
enfatiza a necessidade da se cuidar da relação pedagógica e Kleba (2006) entende que é importante capacitar os educadores para o exercício de sua função.

De fato, em muitos momentos, a indisciplina deve-se à falta de habilidade do professor na relação com o aluno e (AQUINO, 1998) e ações de cunho pedagógico podem tornar-se de suma importância no enfrentamento da indisciplina. A participação em ações sociais promovidas pela escola pode contribuir para que o educando se sinta importante no processo de ensino da escola (VASCONCELLOS, 1999). Embora, nas últimas décadas, tenha havido novas demandas para a escola e novas atribuições para os educadores (AQUINO, 2011), é preciso, como argumentam autores como Ceccom (2009) e Cunha et al. (2009), que a gestão escolar e a orientação educacional invistam na qualidade da relação pedagógica, pois práticas excludentes e inadequadas podem provocar problemas de indisciplina.

Loureiro e Queiroz (2005) observam que, quando o aluno não se sente pertencente ao contexto educacional, pode se colocar em conflito com a escola. Já quando participa da formulação das regras, pode criar o sentimento de compromisso e empenho com sua educação. Nesse sentido, o diálogo é uma ferramenta fundamental para a qualidade da educação. Porém esse diálogo precisa ser desenvolvido pelos demais atores do contexto escolar, em vez de deixar ao professor toda a responsabilidade pela resolução dos conflitos. Boas práticas pedagógicas podem evolver toda a comunidade escolar em prol de uma educação melhor e de qualidade, sempre em busca do desenvolvimento do educando trabalhando suas habilidades e competências (CECCON, 2009).

\section{A indisciplina como resultado da relação conflitiva entre família e escola}

A universalização do ensino fundamental e a expansão do ensino médio mudaram também a face da relação família-escola, diversificando o perfil das famílias que estão em contato com a instituição. São famílias muitas vezes desconhecidas em seus valores e costumes, que não conseguem acompanhar os conteúdos escolares, cujos pais nem sempre tiveram acesso à educação.

A relação família-escola tem sido considerada como um dos pilares contemporâneos para se construir uma educação de qualidade e, pode-se acrescentar, para se organizar um contexto escolar de acordo com valores, regras, maneiras de ser e fazer, ou seja, uma nova disciplina em que todos os atores sociais possam se reconhecer mutuamente. Ora, tudo indica que esses pactos sociais estão longe de serem firmados. Prevalece, ainda, uma relação deficitária entre família e escola, em que esta se coloca como a mais autorizada a definir os rumos da formação das crianças e adolescentes, pelo fato de que é encarregada de transmitir os saberes legitimados na sociedade (CASTRO; REGATIERI, 2009).

Castro e Regatieri (2010) mostram que, na história brasileira, houve marcante desvalorização das famílias, especialmente as pobres, na relação com a escola. As concepções de disciplina eram inspiradas, em grande medida, 
no autoritarismo da sociedade e do Estado. A Constituição Federal de 1988 representou um marco na valorização da família pelo Estado. Instituiu também a educação como direito fundamental que deve ser universalizado. Na consolidação da ordem democrática, famílias e escolas precisam de um novo diálogo (CASTRO; REGATIERI, 2009).

A reafirmação da criança como sujeito de direitos, conforme o Estatuto da Criança e do Adolescente (ECA), Lei n. 8.069 de 1990 (BRASIL, 1990), veio trazer importantes mudanças para a gestão da (in)disciplina na escola e, ao mesmo tempo, na relação entre gerações nas famílias e na relação entre famílias e escola, exigindo um exercício de autoridade sem autoritarismo e dando voz às crianças e adolescentes.

Os estatutos legais que sustentam os direitos das crianças e adolescentes colocam em relevo a corresponsabilidade do Estado, das instituições sociais e das famílias. A ação integrada da escola com a família está prevista na Lei de Diretrizes e Bases da Educação Nacional (LDB), promulgada em 1996. Em seu artigo 14, estabelece que o sistema de ensino deve definir as normas de uma gestão democrática do ensino público na educação básica, enfatizando a participação das comunidades escolares e local em conselhos escolares ou equivalentes. E, no artigo 53, afirma que crianças e adolescentes têm o direito de serem ouvidos e respeitados, tendo garantidas as condições de acesso e permanência na escola. Os pais ou responsáveis têm direito a acompanhar o processo educacional de seus filhos.

Conforme afirmam Castro e Regatieri (2010), o contato amplo da área da educação com alunos, famílias e sociedade é acompanhado da responsabilidade de atuar junto às demais políticas públicas na rede de proteção social a crianças e adolescentes. Na medida em que os direitos infanto-juvenis se consolidam, a escola passa a ter uma interlocução com outros atores sociais, como o Conselho Tutelar e o Ministério Público. Os conflitos são vividos não apenas na esfera privada, mas também na esfera pública, e submetidos à legislação vigente.

Não se trata de negar as dificuldades ligadas às situações de indisciplina ou aos conflitos entre os atores sociais no contexto escolar. Trata-se de mudar a visão sobre esses fenômenos, buscando novas formas de enfrentá-los, dentro da proposta de construção de uma sociedade democrática e a partir da referência da gestão social.

Como afirma Lück (2009), a escola precisa repensar sua prática pedagógica, rever como os professores atuam em sala de aula, se os alunos demonstram interesse pelo conteúdo ensinado, se a conduta adotada está adequada para a turma, acompanhar as ações pedagógicas de cada professor, tanto quanto a postura das famílias, analisando os fatores que contribuem para o aumento de situações de indisciplina.

A criação dos Conselhos Escolares veio abrir possibilidades para a participação da sociedade e das famílias na instituição escolar, podendo influenciar em diversas frentes, dos conteúdos escolares aos comportamentos estudantis punidos ou premiados. Trata-se, entretanto, de uma inovação social ainda recente, cujas experiências exitosas 
apenas começam a ser conhecidas e que ainda precisa de tempo para se consolidar. Certamente, a abordagem da (in)disciplina na escola pode mudar com a maior participação das famílias e da comunidade nos Conselhos Escolares, bem como com a criação de novos dispositivos para participação, incluindo aqueles voltados para as crianças e adolescentes.

Aqui também é interessante observar que há uma possível transformação da escola de arena onde explodem conflitos interpessoais a um território em que se cultivam a compreensão e o diálogo. Enfatiza-se, então, a necessidade do diálogo intercultural na escola contemporânea (CANDAU, 2008).

Ora, dentre os diversos aspectos, ressalta-se a própria natureza do público atendido: são crianças e adolescentes, que são reconhecidos como sujeitos de direitos e pessoas em desenvolvimento (BRASIL, 2006b). A pedagogia do século XX contribuiu em grande parte para o reconhecimento da criança e do adolescente como sujeitos ativos, criativos, proativos e participativos. A necessidade de compreender as peculiaridades do desenvolvimento infantojuvenil também está presente na escola contemporânea.

\section{A indisciplina como fenômeno ligado ao desenvolvimento infanto-juvenil}

É interessante indagar se não haveria uma dimensão da disciplina inerente ao fato da escola lidar com pessoas em desenvolvimento, crianças e adolescentes, que estão aprendendo a ser e a conhecer, com sua vontade de aprender, brincar, crescer e, ao mesmo tempo, com seus conflitos, inseguranças e medos? Não seria a indisciplina ocasional e criativa uma intercorrência natural do desenvolvimento infanto-juvenil? Nesse sentido, Boarini (2013) lembra que o "aluno indisciplinado" não existe isoladamente, mas recebe as influências do seu contexto familiar e social, incluindo aqui a própria escola.

A organização da disciplina na escola precisa prever a existência de situações e atos que confrontam as normas estabelecidas, mas que exigem um tipo de intervenção que seja educativa e não punitiva. Supondo, por exemplo, uma situação de bullying entre crianças, é preciso levar em consideração o desenvolvimento infantil e buscar interromper a situação prevenindo traumas, esclarecendo dificuldades e preconceitos, orientando e construindo novas formas de interação no contexto escolar. Não se trata de aceitar qualquer coisa porque a criança está "vivendo uma fase" ou porque "é coisa de criança". Trata-se de converter os tropeços e desafios em diálogo educativo e construir um contexto em que as crianças possam não apenas compreender as normas, mas também participar de sua elaboração.

No debate sobre a indisciplina na escola, ressurge a importância da formação moral e ética dos educandos na família e na escola. A aproximação entre a psicologia do desenvolvimento humano e a pedagogia aponta para o trabalho interdisciplinar na escola como fundamental ao enfrentamento da indisciplina e para a construção de um 
contexto escolar organizado em torno das necessidades de formação integral das crianças e adolescentes. Seria interessante buscar articular esse debate com a preocupação contemporânea com a formação para a cidadania (BRASIL, 2012).

Essas questões não se tornam fáceis apenas porque há o reconhecimento da infância e da adolescência como fases do desenvolvimento humano bem como da criança e do adolescente como sujeitos de direitos (BRASIL, 2006b). Todavia, é preciso desenvolver as capacidades dos educadores e das famílias para transformar o antigo sistema punitivo e coercitivo em um sistema de educação onde existam normas e também o diálogo em torno delas. De novo, ressalta-se a importância da participação dos diversos atores sociais para a construção da escola como contexto de formação para crianças e adolescentes.

\section{A indisciplina como invasão do espaço escolar pelos conflitos do território}

Finalmente, uma questão que se coloca é a invasão do espaço escolar pelos conflitos do território onde a escola está localizada. Em algumas localidades, a violência urbana envolve os estudantes de forma avassaladora, inclusive com sua inserção em atividades ilegais. Os conflitos do território explodem nos vários lugares de frequentação juvenil, dentre eles, a escola. Porém, não necessariamente esses conflitos foram gerados pela relação pedagógica, pelas desigualdades socioculturais, pelo currículo ou outros elementos internos ao funcionamento da instituição escolar (LOUREIRO; QUEIROZ, 2005; RUOTTI, 2010).

Ruotti (2010) aponta que a violência na escola foi abordada em duas grandes linhas: de um lado, a violência institucional, originada na desigualdade social e no autoritarismo e, de outro, a vulnerabilidade das escolas à violência urbana nas áreas onde estão situadas. Nesses casos, um ambiente escolar submetido a forças que extrapolam a sua dinâmica interna, que criam medo e interferem negativamente nas relações entre os atores sociais do contexto escolar e dificultando também os processos educativos.

Sem dúvida, este é um grande desafio para a gestão escolar. Se nada é feito, instala-se um vazio na instituição escolar, imobilizada diante das situações de violência. Se, por outro lado, a gestão escolar recorre a mecanismos punitivos, a redução dos episódios de violência relacionada aos fatores extraescolares, intensifica-se a violência institucional e os atos arbitrários internos à escola (RUOTTI, 2010).

A situação da escola diante da violência urbana é uma questão ainda mais delicada porque provoca uma tensão entre a necessidade de abrir a escola para a comunidade e proteger a escola da violência que incide na comunidade. Como lembra Ruotti (2010), mais uma vez, o Estado precisa se fazer presente na articulação de diversas políticas públicas, na tentativa de oferecer respostas a esta situação. 


\section{Contribuições da gestão social para a gestão da (in)disciplina na escola}

O presente artigo busca incrementar a leitura da (in)disciplina na escola pela lente da gestão social. Apresenta, assim, o modelo de gestão social e discute algumas de suas possíveis contribuições para o campo da educação, em especial na interface com a gestão escolar.

No Brasil, o modelo de gestão social surge no bojo do processo de democratização das relações entre o Estado e a sociedade. Nas décadas de 1970 e 1980, a sociedade brasileira foi sacudida por movimentos sociais que demandavam novos direitos e a democratização do país. Em 1988, a Constituição Federal institui um marco histórico na reafirmação da cidadania. Contudo, o período também foi caracterizado por projetos societários conflitantes sobre a relação do Estado com a sociedade. Pela influência tanto de interesses internos quanto internacionais, o Estado brasileiro passava a se definir por um modelo de gestão neoliberal, com precário investimento no desenvolvimento social e com políticas públicas compensatórias, ou seja, como Estado mínimo, voltado para as demandas de mercado, o que resulta numa relação conflitiva com as demandas que surgem da sociedade para expansão e democratização das políticas sociais de garantia de direitos (MAIA, 2005).

Em 1995, uma reforma do Estado introduziu os princípios da descentralização político-administrativa e da participação da sociedade civil, o que apontava para um novo modelo de gestão, nomeado gestão social (MAIA, 2005). A gestão social caracteriza-se por "um conjunto de processos sociais com potencial viabilizador do desenvolvimento societário emancipatório e transformador" (MAIA, 2005, p. 78). Ou seja, busca a reafirmação da cidadania e o enfrentamento da questão social ${ }^{1}$, a defesa dos interesses sociais e a garantia dos direitos humanos universais (MAIA, 2005).

Tenório leva adiante essa definição, quando afirma a gestão social como:

[...] o processo gerencial dialógico onde a autoridade decisória é compartilhada entre os participantes da ação (ação que possa ocorrer em qualquer tipo de sistema social - público, privado ou de organizações não governamentais). $\mathrm{O}$ adjetivo social qualificando o substantivo gestão será entendido como o espaço privilegiado de relações sociais onde todos têm o direito à fala, sem nenhum tipo de coação (TENÓRIO, 2008 p. 158).

\footnotetext{
1 Pode-se pensar a questão social, com base em Iamamoto (2001), como a expressão concreta entre a contradição do capital e o trabalho, que gera uma série de manifestações e expressões como a desigualdade, pobreza, exclusão, dentre outros. Para intermediar a questão social, o Estado precisa implementar políticas econômicas e sociais, visando à garantia das necessidades humanas fundamentais.
} 
É importante compreender, todavia, a gestão social como uma construção histórica, que, como já observou Maia (2005), concretiza-se a partir dos processos sociais e projetos societários explícitos ou implícitos, em disputa para a transformação da sociedade.

Cançado, Tenório e Pereira (2011) consideram que é necessário investir na concepção da gestão social, como uma proposta que guarda um caráter de utopia, no sentido de que se coloca como uma referência para a ação, um projeto que orienta a prática, mesmo que, em sua concretização, encontre contradições e tensões, e que jamais se concretize de maneira idêntica àquilo que foi idealizado. Ou seja, a proposta de gestão social serviria para orientar ações em campos diversos da gestão, desde que com participação e visando à emancipação. Assim, Cançado, Tenório e Pereira (2011) reafirmam o conceito de gestão social como:

[...] a tomada de decisão coletiva, sem coerção, baseada na inteligibilidade da linguagem, na dialogicidade e no entendimento esclarecido como processo, na transparência como pressuposto e na emancipação enquanto fim último. Esta síntese não tem caráter prescritivo, em outras palavras, pode haver gestão social para além dela. O intuito aqui é a delimitação do campo não para ‘cercar o que tem dentro' e sim para criar fronteiras para serem mudadas com o decorrer das pesquisas e da própria prática na área.

Pensando na dialética da transformação da sociedade, Maia afirma que, na gestão social, é necessário que se tenha como pilares, na dimensão ética e política, a emancipação social, a cidadania e a democracia. Isto porque, como discute Carvalho (1999), a gestão social deve ser orientada pelas demandas dos cidadãos. Nesse sentido, não se nega a centralidade do Estado, mas coloca-se em relevo a sua responsabilidade no desenvolvimento de políticas públicas e outras ações para responder às demandas sociais e garantir direitos.

De fato, trabalhando com uma nova noção de cidadania, emergente dos movimentos sociais das décadas de 1970 e 1980, Dagnino (2004) enfatiza sua relação com um projeto de democratização, que amplia o espaço da política, entendendo as transformações culturais como parte da política. Além disso:

A nova cidadania assume uma redefinição da ideia de direitos, cujo ponto de partida é a concepção de um direito a ter direitos. Essa concepção não se limita a provisões legais, ao acesso a direitos definidos previamente ou à efetiva implementação de direitos formais abstratos. Ela inclui a invenção/criação de novos direitos, que surgem de lutas específicas e de suas práticas concretas. (DAGNINO, 2004, p. 11)

A nova cidadania implica o reconhecimento dos sujeitos sociais como agentes políticos ativos, definindo seus direitos e lutando por seu reconhecimento e garantia. Assim, não basta ter acesso aos direitos, mas é preciso participar 
de sua definição bem como dos processos ligados à sua efetivação na sociedade, o que leva à questão do controle democrático da sociedade sobre as políticas públicas desenvolvidas pelo Estado (DAGNINO, 2004).

A partir dessas formulações, pode-se pensar na educação como um campo crucial para a construção da nova cidadania. E isto porque, como defendeu Dagnino (2004), a afirmação e o reconhecimento de direitos também exige a transformação das práticas autoritárias no conjunto da sociedade, apontando para uma nova sociabilidade, mais igualitária em todos os níveis, com o reconhecimento da importância do diálogo e do debate, incluindo a negociação dos conflitos para a constituição de uma dimensão ética da vida em sociedade.

Mas a participação não é um fenômeno simples. São necessárias estruturas ou ocasiões que possibilitem o seu acontecimento no contexto social (BOBBIO; MATTEUCCI; PASQUINO, 1998). Também é preciso indagar sobre as situações, os atores sociais, os espaços e os canais envolvidos nesses processos (MILANI, 2008, p. 9-10). Assim, para pensar a participação na escola, é importante pensar nos atores sociais envolvidos no todo da comunidade escolar, inclusive em sua relação com a sociedade ampla. Como afirma Lück (2009):

Em caráter abrangente, a gestão escolar engloba, de forma associada, o trabalho da direção escolar, da supervisão ou coordenação pedagógica, da orientação educacional e da secretaria da escola, considerados participantes da equipe gestora da escola. Segundo o princípio da gestão democrática, a realização do processo de gestão inclui também a participação ativa de todos os professores e da comunidade escolar como um todo, de modo a contribuírem para a efetivação da gestão democrática que garante qualidade para todos os alunos (LÜCK, 2009, p. 23).

Para Lück (2009), o gestor escolar tem a função de nortear os caminhos a serem percorridos pela instituição de ensino, nos âmbitos administrativo e pedagógico, com uma postura proativa que agregue e possibilite o trabalho em equipe. Deve promover ações no campo social, atendendo às demandas do dia a dia, contando com o atendimento aos pais, alunos, professores, funcionários e órgãos públicos, trabalhando de forma participativa. $\mathrm{O}$ trabalho de gestão escolar exige o exercício de múltiplas competências que, por sua vez, necessita capacitação para a ação (LÜCK, 2009, p. 25).

Assim, o trabalho do gestor escolar, se orientado por uma visão de gestão social, buscará se apoiar nos processos participativos de todos os membros da comunidade escolar. Essa orientação abrange questões diversas, dentre elas a questão da disciplina (como organizar o cotidiano da escola, normas, valores coletivos, dentre outros aspectos) e, portanto, da indisciplina (o que fazer quando essa organização sofre desvios ou confrontações). 
Claro está que, no dia a dia da escola, surgem questões que exigem respostas imediatas. Nas diversas interações vividas (como professor-aluno, aluno-aluno e outras), muitas são as situações que colocam desafios. Essas situações, no entanto, podem e devem ser alvo de reflexão em outros momentos, buscando ir além das atitudes imediatistas e construir referências para a ação pedagógica, de forma que a escola busque o diálogo na deliberação sobre os valores que a organizam (CHRISPINO, 2007).

O modelo da gestão social contribui para a gestão escolar na medida em que problematiza a importância da participação dos atores sociais, desde as grandes decisões até os conflitos que surgem no cotidiano da instituição, como a (in) disciplina, quer seja motivada por razões individuais ou coletivas. Seja o diálogo com uma família, uma reunião do Conselho Escolar, ou o desenvolvimento de projetos comunitários, a gestão escolar pode se debruçar sobre essas questões a partir de um modelo de gestão social, em que são pilares: a participação, o diálogo, o contato com a comunidade, a relação da escola com a sociedade, a democratização do acesso e da qualidade de ensino e a formação para a cidadania.

Nessa perspectiva, além da promoção intelectual dos alunos, a escola se junta às demais instâncias da sociedade para constituir-se em um ambiente formativo para a cidadania. Não se atribuir à escola a responsabilidade única de formar cidadãos, como se isto fosse algo puramente "técnico". Trata-se de incorporar a escola no conjunto de instituições que se organizam pelos princípios de uma nova cidadania e uma nova sociabilidade.

Seguindo nesse argumento, o presente artigo aborda, a seguir, as propostas do Plano Nacional de Educação em Direitos Humanos (PNEDH) e das Diretrizes Nacionais de Educação em Direitos Humanos (DNEDH).

\section{A proposta do PNEDH e das DNEDH: novas bases para a construção da disciplina}

Em 1948, a Organização das Nações Unidas aprovou a Declaração Universal dos Direitos Humanos (DUDH) que, dentre outras recomendações, defendia a necessidade da Educação em Direitos Humanos (EDH) como elemento fundamental na construção das democracias e de uma cultura de paz. Como signatário da DUDH, o Brasil deve ser responsável pela promoção, defesa e garantia dos direitos humanos no país, o que precisa ser apoiado com políticas públicas e ações concretas. Dentre elas, ressalta-se, como preocupação do presente artigo, a responsabilidade pelo desenvolvimento da EDH no país.

Em 2003, o Brasil elaborou a sua primeira versão do Plano Nacional de Educação em Direitos Humanos (PNEDH), reescrita em 2006 (BRASIL, 2006a), na esteira da aprovação, pela ONU, em 2005, do Plano Mundial de Educação em Direitos Humanos (PMEDH). Em 2012, foram aprovadas (BRASIL, 2012) as Diretrizes Nacionais 
para a Educação em Direitos Humanos (DNEDH) e foi publicado o PMEDH em língua portuguesa (UNESCO, 2012 a; UNESCO, 2012b). Pode-se observar a estreita correlação entre esses documentos, tanto no conteúdo quanto no momento histórico em que vêm a lume, criando espaço para a discussão sobre educação, direitos humanos e cidadania em diversos setores da sociedade brasileira.

Para embasar a presente discussão, apresenta-se, em seguida, uma síntese das propostas do PNEDH e das DNEDH para o ensino fundamental e médio. Antes, porém, é importante explicitar o conceito de DH que orienta este trabalho.

Os Direitos Humanos nascem das lutas pela dignidade e pela liberdade, como uma construção histórica, que não para no tempo, mas que continua em debate. Constituem um conjunto universal, indivisível, interdependente e interrelacionado, de forma que o acesso a um direito só se efetiva plenamente quando existe também o acesso a outros direitos. E é crucial reconhecer que ainda há grandes diferenças sociais no acesso aos direitos humanos.

Os direitos de cidadania (DC) podem ser entendidos como aqueles inscritos na Constituição Federal e demais preceitos do ordenamento jurídico. Porém, para que os DC sejam efetivos, é fundamental que o Estado desenvolva políticas públicas que promovam e garantam esses direitos. Assim, os DH ganham materialidade com os DC conquistados. Isto nos leva a refletir que, para desenvolver ações em EDH, de uma maneira coerente com a nossa realidade, precisamos abordar questões de cidadania.

Neste artigo, adota-se a noção de cidadania descrita por Lafer (1997) que reafirma o conceito (desenvolvido pela filósofa Hanna Arendt), de que a cidadania é o direito a ter direitos, mas que é o direito de pertencer a uma comunidade política que possibilita, por sua vez, a definição e o acesso aos direitos humanos (LAFER, 1997, p. 58). Justamente por isto a EDH só se torna efetiva quando é apropriada pelos sujeitos a partir das questões vividas em seu contexto social, cultural e político. É o pertencimento a um contexto que pode suscitar questões para os DH, a EDH e a formação para a cidadania (AFONSO; ABADE, 2013).

Trabalha-se também com a perspectiva introduzida por Demo (1995, apud AFONSO; ABADE, 2013), quando diferencia a cidadania emancipatória da cidadania tutelada e da cidadania assistida. Na cidadania emancipatória, é reconhecido o "direito a ter direitos" e se atribui ao Estado a responsabilidade pela garantia desses direitos. A cidadania emancipatória é relacionada à capacidade de participar de forma consciente e crítica da sociedade.

Neste artigo, a discussão da (in)disciplina na escola liga-se à cidadania emancipatória. A gestão da (in)disciplina não pode estar ligada à submissão a um status quo. É necessário que a ordem construída e a qualidade de ensino dialoguem com a formação para a cidadania e que os educandos possam refletir sobre direitos, em seu contexto de vida, desenvolvendo capacidades para a participação social. 
Apesar do direito à educação estar inscrito na Constituição Federal de 1988 e na Lei de Diretrizes e Bases da Educação (1996), a escola brasileira ainda reflete as desigualdades econômicas, sociais e culturais do país. O fortalecimento do direito à educação precisaria andar lado a lado ao fortalecimento da cidadania emancipatória. Nesse sentido, a seguir, são apresentadas as propostas do PNEDH (BRASIL, 2006a) e das DNEDH (BRASIL, 2012).

No PNEDH, a educação em direitos humanos visa à conscientização para o respeito à dignidade humana, $\mathrm{o}$ exercício dos direitos e a formação para a participação cidadã (PNEDH, 2006). O PNEDH apresenta seus objetivos e linhas de ação em cinco eixos: (1) educação básica; (2) educação superior; (3) educação não formal; (4) educação dos profissionais dos sistemas de justiça e segurança; e (5) educação e mídia (grifo nosso).

No PNEDH (BRASIL, 2006a), a EDH é vista como um processo sistemático, que articula diversas dimensões na formação do sujeito de direitos, desde ações educativas até aquelas voltadas para projetos sociais, inclusive em trabalho conjunto com diversas políticas públicas. Essas dimensões são assim definidas: (a) apreensão de conhecimentos historicamente construídos sobre direitos humanos e a sua relação com os contextos internacional, nacional e local; (b) afirmação de valores, atitudes e práticas sociais que expressem a cultura dos direitos humanos em todos os espaços da sociedade; (c) formação de uma consciência cidadã capaz de se fazer presente nos níveis cognitivo, social, ético e político; (d) desenvolvimento de processos metodológicos participativos e de construção coletiva, utilizando linguagens e materiais didáticos contextualizados; (e) fortalecimento de práticas individuais e sociais que gerem ações e instrumentos em favor da promoção, da proteção e da defesa dos direitos humanos, bem como da reparação das violações.

O PNEDH propõe uma reflexão sobre valores, atitudes e práticas sociais relacionados à cultura dos direitos humanos, como base para uma consciência cidadã. Nesse sentido, é importante desenvolver mais do que o acesso à informação. Fernandes e Paludeto (2010 apud AFONSO; ABADE, 2013) acrescentam que a EDH deve contribuir para efetivar a cidadania, desenvolver valores e atitudes bem como competências para a participação na sociedade.

Em relação à postura pedagógica, o PNEDH sugere a adoção de processos metodológicos participativos, de construção coletiva, com linguagens e materiais didáticos que promovam os valores, as atitudes, as ações, as estratégias e os instrumentos em favor da defesa, da promoção e ampliação dos direitos humanos (BRASIL, 2006a). Essa postura é reafirmada nas Diretrizes Nacionais para a Educação em Direitos Humanos (BRASIL, 2012).

Aprovadas pelo Conselho Nacional de Educação (Resolução CNE/CP 1/2012), as DNEDH deverão ser inseridas nas diretrizes curriculares; integrada aos conteúdos, metodologias e formas de avaliação; através de pedagogias participativas, incluindo temas como gênero e identidade, raça e etnia, orientação sexual e religião, entre outras (FERNANDES; PALUDETO, 2010 apud AFONSO; ABADE, 2013). 
As DNEDH definem como objetivo central a formação para a vida e para a convivência, no exercício cotidiano dos direitos, como forma de vida e de organização social, política, econômica e cultural. As instituições de ensino devem planejar e desenvolver ações de EDH adequadas aos seus diferentes sujeitos e contextos, em ações que devem ser acompanhadas pelos Conselhos de Educação. A inserção de conhecimentos concernentes à EDH, na organização dos currículos da Educação Básica pode ocorrer através de ações transversais e temas interdisciplinares, em disciplinas ou outras formas. Para dar sustentabilidade a essa proposta, os educadores precisam ser capacitados para atuar em EDH.

$\mathrm{O}$ debate em torno da EDH tem abordado a sua adequação às questões e reivindicações atuais da sociedade brasileira, principalmente no que diz respeito às desigualdades sociais e às diferenças em uma sociedade multicultural. Candau (2012 apud AFONSO; ABADE, 2013) argumenta que a EDH deve ser embasada no diálogo entre culturas e grupos sociais, buscando-se um multiculturalismo crítico, aberto e interativo. Para tal, seria necessário rever conceitos e preconceitos e promover experiências de interação que possam favorecer a percepção da alteridade no contexto escolar. Acredita-se que essas iniciativas são positivas para a construção da disciplina na escola de uma forma que seja coerente com a promoção da cidadania, e, mais especificamente, da cidadania emancipatória.

\section{Considerações finais}

Questionar a (in)disciplina e tentar compreender sua gênese na escola não significa abrir mão de um sistema de valores que promova uma educação de qualidade, o desenvolvimento humano e social, enfatizando uma sociedade mais justa e igualitária. Significa buscar nova ancoragem para os valores, não mais fundada na rigidez, discriminação e desigualdade. Como afirma Andrade (2010), a educação em valores não pode ser uma mera incorporação acrítica de um referencial dado, mas precisa incentivar o pensamento como desconstrução e reconstrução do mundo, no contexto da vida dos educandos.

Nessa perspectiva, a gestão social da (in)disciplina no espaço escolar ganha relevância para os diversos atores sociais no cotidiano escolar, de forma a potencializar os processos participativos e consistentes com o respeito à cidadania e aos direitos humanos.

A (in)disciplina escolar apresenta-se como um fenômeno complexo, cuja compreensão precisa articular diferentes fatores em um sistema mais amplo. Neste artigo, foram abordados múltiplos fatores que podem concorrer para o fenômeno, e que são, muitas vezes, correlacionados, em uma visão complexa.

Foi discutido que a indisciplina pode ser compreendida como resistência a uma ordem hegemônica, como resultante de conflitos entre a família e a escola, de conflitos interpessoais, dos processos de desenvolvimento infantojuvenil e da exposição da escola à violência territorial e urbana. 
Buscando contribuir para a discussão, sem pretensão de exaurir a questão, foram também levantados diversos aspectos da gestão social e da educação em direitos humanos que poderiam fazer face à indisciplina, construindo uma disciplina escolar consistente com uma cidadania emancipatória. Citem-se, por exemplo:

- Valorização das crianças e adolescentes e suas famílias, em seu contexto sociocultural;

- Enfrentamento das formas de discriminação social no contexto escolar;

- Abertura para a interculturalidade na escola;

- Incentivo à participação na escola das famílias e da comunidade;

- Fortalecimento dos conselhos escolares;

- Conhecimento da realidade sociocultural das famílias;

- Desenvolvimento de ações visando o fortalecimento da relação família-escola;

- Capacitação de professores (para lidar com conflitos, conhecer o desenvolvimento infanto-juvenil e os direitos das crianças e adolescentes, potencializar o processo de ensino-aprendizagem, dialogar com as famílias, conhecer e atuar com o PNEDH);

- Incremento do diálogo, mediado por instâncias e atores sociais do contexto escolar;

- Discussão de normas em instâncias coletivas;

- Discussão de casos em instâncias coletivas (resguardos os cuidados éticos);

- Participação da escola na rede de serviços no território, em parceria com as políticas públicas;

- Desenvolvimento de ações de EDH na escola e na comunidade.

Sem pretensão de esgotar a questão, buscou-se, neste artigo, compreender o fenômeno da (in)disciplina na escola a partir de questões contemporâneas, como a cidadania e a gestão social na escola. Espera-se ter colaborado na construção de uma matriz de possibilidades que venha a auxiliar na análise do fenômeno da (in)disciplina na escola, na prática dos educadores, em fóruns educacionais diversos e, não menos importante, para futuras pesquisas.

\section{Referências}

AFONSO, M. L. M.; ABADE, F. L. Jogos para pensar: Educação em Direitos Humanos e formação para a cidadania. Belo Horizonte: Autêntica, 2013.

ANDRADE, Marcelo. A banalidade do mal e as possibilidades da educação moral: contribuições arendtianas. Revista Brasileira de Educação, v. 15, n. 43, jan.-abr. 2010, p. 109-125. <http://dx.doi.org/10.1590/S1413-24782010000100008>.

AQUINO, J. G. Indisciplina na escola: alternativas teóricas e práticas. São Paulo: Summus, 1996. 
AQUINO, J. G. A indisciplina e a escola atual. Revista Faculdade de Educação, USP, v. 42, n. 2, p. 181-204, jul. 1998. <http://dx.doi. org/10.1590/S0102-25551998000200011>.

AQUINO, J. G. Da (contra)normatividade do cotidiano escolar: problematizando discursos sobre a indisciplina discente. Cadernos de Pesquisa, v. 41, n. 143, p. 456-484, 2011. <http://dx.doi.org/10.1590/S0100-15742011000200007>.

BOARINI, M. L. Indisciplina escolar: uma construção coletiva. Psicologia Escolar e Educacional, v. 17, n. 1, p. 123-131, jun. 2013. $<$ http://dx.doi.org/10.1590/S1413-85572013000100013>.

BOBBIO, N.; MATTEUCCI, N.; PASQUINO, G. Dicionário de política I. Brasília: Editora Universidade de Brasília, 1998.

BOURDIEU, P. Capital simbólico e classes sociais. Novos estudos CEBRAP [online], n. 96, p. 105-115, 2013. <http://dx.doi. org/10.1590/S0101-33002013000200008>.

BRASIL. Constituição Federal Brasileira 1988. Brasília, 1988.

BRASIL. Lei de Diretrizes e Bases da Educação Nacional 9.394, de 20 de dezembro de 1996. Disponível em: <http://www.planalto. gov.br/ccivil_03/leis/19394.htm>. Acesso em 15/11/2013.

BRASIL. Plano Nacional de Educação em Direitos Humanos. Brasília: Secretaria Especial dos Direitos Humanos, Ministério da Educação, Ministério da Justiça, UNESCO, 2006a.

BRASIL. Plano Nacional de Promoção, Proteção e Defesa dos Direitos das Crianças e Adolescentes à Convivência Familiar e Comunitária. Brasília: CONANDA, 2006b.

BRASIL. Lei 8.069 de 13 de julho de 1990, que dispõe sobre o Estatuto da Criança e do Adolescente. Brasília, 1990.

BRASIL. Ministério da Educação. Conselho Nacional de Educação. Diretrizes Nacionais para a Educação em Direitos Humanos. Brasília, 2012.

CANÇADO, A. C.; TENÓRIO, F. G.; PEREIRA, J. R. P. Gestão social: reflexões teóricas e conceituais. Cadernos EBAPE.BR, Rio de Janeiro, v. 9, n. 3, p. 681-703, set. 2011.

CANDAU, V. M. F. Direitos humanos, educação e interculturalidade: as tensões entre igualdade e diferença. Revista Brasileira de Educação, v. 13, n. 37, p. 45-56, abr. 2008. <http://dx.doi.org/10.1590/S1413-24782008000100005>.

CARVALHO, M. do C. B. Alguns apontamentos para o debate. In: RICO, E. de M.; RAICHELIS, R. (Org.). Gestão Social: uma questão para o debate. São Paulo: Educ/IEE/PUCSP, 1999. p. 19-29.

CASTRO, J. M.; REGATTIERI, M. (Org.). Interação escola-família: subsídios para práticas escolares. Brasília: UNESCO, MEC, 2009. CECCON, C. et al. Conflitos na escola: modos de transformar - dicas para refletir e exemplos de como lidar. São Paulo: CECIP Imprensa Oficial do Estado de São Paulo, 2009. 208 p.

CUNHA, M. de F. P. C.; VALENTIN, A. S.; LISBOA, D. C. S.; MONTEIRO, E. C. M.; XANDER, P. Indisciplina e a noção de justiça em adolescentes escolares. Educação em Revista, n. 35, p. 197-210, 2009. <http://dx.doi.org/10.1590/S0104-40602009000300015>.

CHRISPINO, Á. Gestão do conflito escolar: da classificação dos conflitos aos modelos de mediação. Ensaio: avaliação e políticas públicas em educação [online], v. 15, n. 54, p. 11-28, 2007. <http://dx.doi.org/10.1590/S0104-40362007000100002>. 
DAGNINO, E. ¿Sociedade civil, participação e cidadania: de que estamos falando? In: MATO, D. (Org.). Políticas de ciudadanía y sociedad civil en tiempos de globalización. Caracas: FACES, Universidad Central de Venezuela, 2004. p. 95-110.

FREIRE, P. Educação como prática da liberdade. Rio de Janeiro: Paz e Terra, 1967.

FREIRE, P. Pedagogia da Autonomia: saberes necessários à prática educativa. 27. ed. São Paulo: Paz e Terra, 2003.

GADOTTI, M. Boniteza de um sonho: ensinar-e-aprender com sentido. São Paulo: Livraria e Instituto Paulo Freire, 2008.

Iamamoto, M. V. A questão social no capitalismo. Revista Temporalis, n. 03, jan.-jun. 2001.

IBGE - Instituto Brasileiro de Geografia e Estatística. Pesquisa nacional por amostra de domicílios (PNAD). Brasília, 2009.

KLEBA, J. B. Tecnologia, ideologia e periferia: um debate com a filosofia da técnica de Álvaro Vieira Pinto. Convergencia, Universidad Autónoma del Estado do México, v. 13, n. 42, p. 73-93, set. 2006.

LAFER, C. A reconstrução dos direitos humanos: a contribuição de Hanna Arendt. Estudos Avançados, v. 11, n. 30, p. 55-65, maioago. 1997.

LOUREIRO, A. C. A. M.; QUEIROZ, S. S. de. A concepção de violência segundo atores do cotidiano de uma escola particular: uma análise psicológica. Psicologia: ciência e profissão, v. 25, n. 4, p. 546-557, 2005.

LÜCK, H. A evolução da gestão educacional a partir de mudança paradigmática 2009. Disponível em: <http://progestaoead.files. wordpress.com/2009/09/a-evolucao-da-gestaoeducacional-hluck.pdf>. Acesso em: 17 nov. 2013.

LÜCK, H. Dimensões de gestão escolar e suas competências. Curitiba: Editora Positiva, 2009.

MAIA, M. Gestão social: reconhecendo e construindo referenciais. Revista Virtual Textos \& Contextos, n. 4, ano IV, dez. 2005.

MILANI, C. R. S. O princípio da participação social na gestão de políticas públicas locais. RAP, Rio de Janeiro, v. 42, n. 3, p. 551-579, maio-jun. 2008.

NOGUEIRA, C. M. M.; NOGUEIRA, M. A. A sociologia da educação de Pierre Bourdieu: limites e contribuições. Educação e Sociedade [online], v. 23, n.78, p. 15-35, 2002. <http://dx.doi.org/10.1590/S0101-73302002000200003>.

PELOSO, F. C.; PAULA, E. M. A. T. de. A educação da infância das classes populares: uma releitura das obras de Paulo Freire. Educação em Revista [online], v. 27, n. 3, p. 251-280, 2011. <http://dx.doi.org/10.1590/S0102-46982011000300013>.

RATTO, A. L. S. Disciplina, vigilância e pedagogia. Cadernos de Pesquisa, São Paulo, v. 37, n. 131, p. 481-510, 2007. <http://dx.doi. org/10.1590/S0100-15742007000200012>.

RUOTTI, C. Violência em meio escolar: fatos e representações na produção da realidade. Educação e Pesquisa, v. 36, n. 1, p. 339-355, 2010. <http://dx.doi.org/10.1590/S1517-97022010000100010>.

SNYDERS, G. Escola, classe e luta de classes. São Paulo: Centauro, 2005.

SOUZA, L. G. S.; QUEIROZ, S. S. de; MENANDRO, M. C. S. E quando os estudantes pedem mais disciplina? Estudo de caso e reflexões sobre autonomia e vida escolar. Psicologia: ciência e profissão [online], v. 30, n. 3, p. 524-539, 2010.

TENÓRIO, F. G. (Re)Visitando o conceito de gestão social. In: SILVA Jr, J.; MÂSIH, R. et al. (Org.). Gestão social: práticas em debate, teorias em construção. Fortaleza: Imprensa Universitária, 2008. 
UNESCO - Organização das Nações Unidas para a Educação, a Ciência e a Cultura. Alto Comissariado das Nações Unidas para Direitos Humanos (ACNUDH). Plano de Ação: Programa Mundial de Educação em Direitos Humanos. Primeira Fase. Brasília, 2012 a. Disponível em: <http://unesdoc.unesco.org/images/0014/001478/147853por.pdf>. Acesso em: 12 dez. 2013.

UNESCO - Organização das Nações Unidas para a Educação, a Ciência e a Cultura. Alto Comissariado das Nações Unidas para Direitos Humanos (ACNUDH). Plano de Ação: Programa Mundial de Educação em Direitos Humanos. Segunda Fase. Brasília, $2012 b$. Disponível em: <http://unesdoc.unesco.org/images/0021/002173/217350por.pdf>. Acesso em: 12 dez. 2013.

VARES, S. F. de. Reprodução social e resistência política na escola capitalista: um retorno às teorias reprodutivistas. Revista Reflexão e Ação, Santa Cruz do Sul, v. 20, n. 2, p. 309-326, jul.-dez.2012.

VASCONCELLOS, C. dos S. Planejamento: Projeto de ensino aprendizagem e Projeto Político Pedagógico - elementos metodológicos para elaboração e realização. São Paulo: Libertad, 1999.

VASCONCELLOS, M. D. O trabalho pedagógico na construção social da excelência escolar. Educação e Sociedade, v. 27, n. 97 , p. 1089-1112, dez. 2006. <http://dx.doi.org/10.1590/S0101-73302006000400002>.

\section{Endereço para correspondência:}

Luciano Henrique Barcelos

Av. João Pinheiro, 515

30130-180 Belo Horizonte, MG, Brasil

<lucianohenriquebarcelos@hotmail.com>

Recebido em: junho/2014

Aceito em: dezembro/2014 